\title{
PADRÃO DE ASSENTAMENTOS PRÉ-COLONIAIS NA SESMARIA JAGUARIBE - PE
}

\section{Marcos Victor Gomes de Oliveira}

\author{
Bruno de Azevêdo Cavalcanti \\ Tavares**
}

\section{Cláudia Alves de Oliveira***}

RESUMO: O trabalho trás uma análise da ocupação de grupos pré-coloniais na área da Sesmaria Jaguaribe, localizado nos municípios de Abreu e Lima, Igarassu e Paulista, na região metropolitana de Recife. A pesquisa buscou compreender os critérios de escolha dos grupos pré-coloniais. Para assim, estabelecer um padrão de distribuição dos assentamentos pré-coloniais por toda a extensão da Sesmaria Jaguaribe, PE. Para tanto, foi efetuado um levantamento das pesquisas arqueológicas já realizadas na área de estudo, assim foi possível elencar os sítios pré-coloniais e suas coordenadas. A partir das posições dos sítios e dos dados topográficos, foi possível criar um banco de dados em SIG com informações acerca do posicionamento dos sítios e sua relação com variáveis da paisagem, e partir dessas análises, procurar inferir padrões de assentamentos. As análises realizadas revelaram que a grande maioria dos sítios pré-coloniais, estavam dispostos em topos de tabuleiros, isso pode ter relação com o posicionamento de boa visibilidade e por se tratar de uma área com maior estabilidade em termos de processos erosivos. Essa posição de sítios em topos de tabuleiros pode significar que os grupos, procuravam se estabelecer nesses setores da paisagem, devido a proximidade e boa visibilidade de recursos.

Palavras-chaves: Pré-Colonial; Padrão de Assentamentos; Sesmaria Jaguaribe.

ABSTRACT: This work presents an analysis of the occupation of pre-colonial groups in the area of Sesmaria Jaguaribe, located in the municipalities of Abreu and Lima, Igarassu and Paulista, in the metropolitan region of Recife.

*Arqueólogo formado pela Universidade Federal de Pernambuco - UFPE marcosvoliveira@outlook.com

**Departamento de Arqueologia da Universidade Federal de Pernambuco - UFPE bruno.tavares@ufpe.br

*** Departamento de Arqueologia da Universidade Federal de Pernambuco - UFPE oliva2006@gmail.com
The research sought to understand the criteria for choosing pre-colonial groups. In order to establish a pattern of distribution of pre-colonial settlements throughout Sesmaria Jaguaribe, PE. For that, a survey of the archaeological researches already carried out in the study area was done, so it was possible to list the pre-colonial sites and their coordinates. From the positions of the sites and the topographic data, it was possible to create a database in GIS with information about the positioning of the sites and their relationship with landscape variables, and from these analyzes, seek to infer settlement patterns. The analysis revealed that the vast majority of pre-colonial sites were arranged in tops of boards, this may be related to the positioning of good visibility and because it is an area with greater stability in terms of erosive processes. This position of sites on board tops could mean that the groups sought to establish themselves in these sectors of the landscape because of the proximity and good visibility of resources. Keywords: Pre-Colonial; Settlement Pattern; Sesmaria Jaguaribe. 


\section{Introdução}

A área da antiga Sesmaria Jaguaribe apresenta um vasto campo de pesquisa capaz de fornecer dados inéditos sobre o período colonial e pré-histórico do Brasil. Historicamente, foi um importante centro produtor para a área litorânea da capitania de Pernambuco, tanto na fabricação do açúcar quanto de outros produtos importantes, principalmente para a economia e movimentação do comércio interno da referida capitania, tais como a cal, os produtos oriundos da Fazenda de São Bento, o pescado proveniente de seus estuários, a exploração de suas matas, entre outros (Oliveira, 2011; Santos, 2009).

A área de estudo é caracterizada pela presença de sítios arqueológicos no contexto das colinas e dos tabuleiros costeiros da região metropolitana do Recife. Diante da disposição das ocupações, o trabalho tem como objetivo, estabelecer um padrão de distribuição dos assentamentos pré-coloniais por toda a extensão da Sesmaria Jaguaribe, analisando espacialmente os elementos da paisagem que podem ter atuado como elementos facilitadores para a ocupação da Sesmaria.

Para se chegar a esse padrão de assentamentos, foi essencial fazer análises ambientais, como tentativa para compreender, de forma clara, o critério de escolha dos povos pré-coloniais. A partir disso foi levantada uma problemática, que recai na seguinte questão: Quais seriam os atributos que compõem os elementos da paisagem, que possibilitaria a ocupação dos grupos pré-coloniais nas regiões de topo das colinas e tabuleiros que ocorrem na Sesmaria Jaguaribe?

O trabalho se alicerça na hipótese de que grupos pré-coloniais procuram se estabelecer em locais com baixa declividade, em áreas onde há boa visibilidade do entorno e que a captação de recursos seja facilitada pela paisagem que o cerca. Para embasar essa hipótese, se fez necessário uma pesquisa bibliográfica para que se tivesse como referencial as abordagens teóricas já realizadas para padrões de assentamentos de grupos pré-coloniais (Butzer, 1989; Boado, 1999; Sanjuán, 2005).

Aliado a teoria de análise arqueológica do território (Sanjuán, 2005), a abordagem da arqueologia espacial postulada inicialmente por Clarke (1977) se alicerçou com o uso das geotecnologias. Elaboração de mapas de análise espacial, com o auxílio do software ArcGIS. Mapas temáticos com informações de hipsometria, geologia, solos, compartimentos geomorfológicos, declividade e aspecto da encosta são primordiais para a compreensão dos elementos ambientais que podem atuar na distribuição de locais propícios para ocupação. 
A análise conjunta dos elementos espaciais e os elementos culturais são fundamentais para a discussão sobre como os elementos da paisagem atuaram na escolha dos grupos pré-coloniais por determinadas áreas em detrimento de outras.

\section{Arqueologia da Paisagem}

A abordagem processualista enfatiza o valor do contexto ecológico na essência da cultura e do intercâmbio cultural. Para Binford (1962) a cultura é um sistema de meios extra somáticos de adaptação, com os quais os seres humanos buscam sua adaptação ao meio físico e social que o rodeia. Sanjuán (2005) aponta três contribuições da abordagem processualista, o surgimento da Arqueologia de Assentamentos, o uso de novas técnicas e metodologia como análises paleoambientais e geoarqueológicas e a terceira grande contribuição da Arqueologia Processual foi a introdução do conceito materialista de cultura.

Foi na década de 1980, com o surgimento da Arqueologia Pós-processual, que houve um interesse maior em estabelecer uma metodologia arqueológica, que analisasse a relação da adaptação humana com o meio ambiente. Logo, foram surgindo vertentes da arqueologia ligadas às relações entre o meio ambiente e o registro arqueológico, com influência marcante do Pós-processualismo (Sanjuán, 2005; Boado, 1991; Boado 1999).

O padrão de assentamento dos povos pré-coloniais tem estado literalmente ligado a paisagem e aos seus componentes. Um meio de interpretar a relação de grupos humanos e o meio ambiente tem sido a Arqueologia da Paisagem. Esta por sua vez, tem como objetivo entender como foi, ao longo do tempo, a relação entre grupos humanos e o ambiente físico e biótico, compreendendo como os grupos habitaram e modificaram a paisagem, e como esta influência, modifica e limita as comunidades (Madeira, 2016).

É possível perceber que os estudos da Arqueologia da Paisagem são importantes para compreender, quais foram os critérios de ocupação dos grupos pré-coloniais. E como esses grupos faziam uso do meio físico-natural.

\section{Padrão de Assentamentos}

Nos anos de 1950 e 1960, sugiram os primeiros estudos sobre padrões de assentamentos. Especificamente com Willey em 1953, que realizou análises arqueológicas em nível regional para compreender sistemas de assentamento, das sociedades pré-incas do Vale Virú, no Peru. Sua pesquisa procurava reconstruir a evolução dos assentamentos pré-históricos da região. 
Segundo Beber (2004), o padrão de assentamento é evidente através de uma sucessão de ocupações em um determinado espaço quer por sociedades diferentes, quer pelas modificações que um grupo pode apresentar e seu padrão de assentamento, fruto das alterações em seu modo de vida.

A Arqueologia de Assentamento busca entender as relações que os sítios arqueológicos mantiveram com o contexto ambiental, procurando estabelecer os critérios para compreender como determinadas comunidades ocuparam determinados lugares na paisagem.

Em relação a estratégia de subsistência, o elemento essencial é a análise de captação de recursos, esta consiste na busca das relações entre os assentamentos e o meio físico que vive um determinado grupo, o qual consegue recursos e desenvolve sua tecnologia e organização socioeconômica nesse ambiente (Butzer,1989; Sanjuán, 2005).

Como a Arqueologia de Assentamento busca estabelecer os critérios para compreender como algumas comunidades ocuparam determinados lugares na paisagem, surgem algumas perguntas. Sanjuán (2005) aponta algumas delas: Qual a distância dos recursos do assentamento? Quais foram os critérios de um grupo para decidir ocupar um ponto da paisagem? Uma das problemáticas que surge nesse trabalho é, por que os sítios pré-coloniais estavam dispostos em sua grande maioria nos topos dos tabuleiros e colinas? Para responder essas perguntas, são utilizadas técnicas e ferramentas das análises espaciais, que trazem para a arqueologia, um estudo do comportamento humano mais relativista e contextualizado (Sanjuán, 2005).

A organização dos dados arqueológicos de um ponto de vista espacial pode permitir outro viés interpretativo de como os grupos humanos pré-históricos faziam uso do meio físico-natural. Uma abordagem que vem sendo utilizada para realizar as análises de cunho espacial, com o objetivo de compreender e estabelecer padrões para a distribuição de sítios é o Sistema de Informação Geográfica (SIG) (Santos, 2006). A utilização do SIG na arqueologia facilita o mapeamento dos sítios e a espacialização dos dados arqueológicos (Conolly \& Lake, 2009; Morais, 2000; Mützenberg, 2007).

\section{Localização e Caracterização Ambiental}

A Sesmaria Jaguaribe, corresponde aos municípios de Abreu e Lima, Igarassu e Paulista, localizados na Zona Norte do litoral do Estado de Pernambuco, na região metropolitana de 
Recife (Figura 1). Seu acesso se dá pela rodovia federal BR-101, ficando a aproximadamente 20 km de distância da capital Recife.

\section{Contexto Geológico e Geomorfológico}

Os terrenos do Litoral Norte onde está localizada a Sesmaria Jaguaribe, estão constituídos, na maior parte, por depósitos Terciários e Quaternários, e está inserido em quatro grupos diferentes de unidades geológicas. Essas unidades geológicas são constituídas das Formações Barreiras, Beberibe, Gramame e Maria Farinha, sendo a Formação Barreiras, a de maior extensão dentre as formações constituintes da Bacia Sedimentar Costeira Pernambuco-Paraíba (CPRH, 2001).

O contexto geomorfológico da Sesmaria está atrelado aos setores colinosos pluriconvexos estruturados ora pela Formação Barreiras ora por mantos de intemperismo do substrato PréCambriano e as áreas de várzeas, estas compondo os níveis de base locais da drenagem que verte para o Atlântico.

\section{Clima e Hidrografia}

A Sesmaria Jaguaribe está localizada no domínio climático Tropical Úmido. Os setores do Nordeste oriental, especificamente da costa pernambucana são caracterizados por um regime de chuvas de outono-inverno, com temperaturas em média de $26^{\circ} \mathrm{C}$. Em termos hidrográficos a Sesmaria Jaguaribe, está inserida dentro das Bacias hidrográficas do rio Timbó, Paraíba, Igarassu e Botafogo/Arataca, bem como pelas micro bacias que drenam os terraços marinhos.

\section{Vegetação e Fauna}

A cobertura original da vegetação no litoral Norte de Pernambuco corresponde ao domínio de Mata Atlântica, porém sua vegetação e sua diversidade biológica vêm sofrendo grave destruição desde o início da colonização do Brasil (Dean, 1996). Na época da colonização, boa parte da Mata Atlântica foi degradada em prol dos cultivos da cana-de-açúcar e pelo cultivo de coco.

A Sesmaria Jaguaribe possui um rico local de reprodução de espécies da fauna e flora aquática, merecem destaque na área os estuários e os manguezais do rio Timbó e do canal de Santa Cruz. O manguezal do rio Timbó nos municípios de Paulista e Abreu e Lima é importante também, para a sobrevivência das pessoas que vivem da exploração de bens naturais (Santos, 2009). 


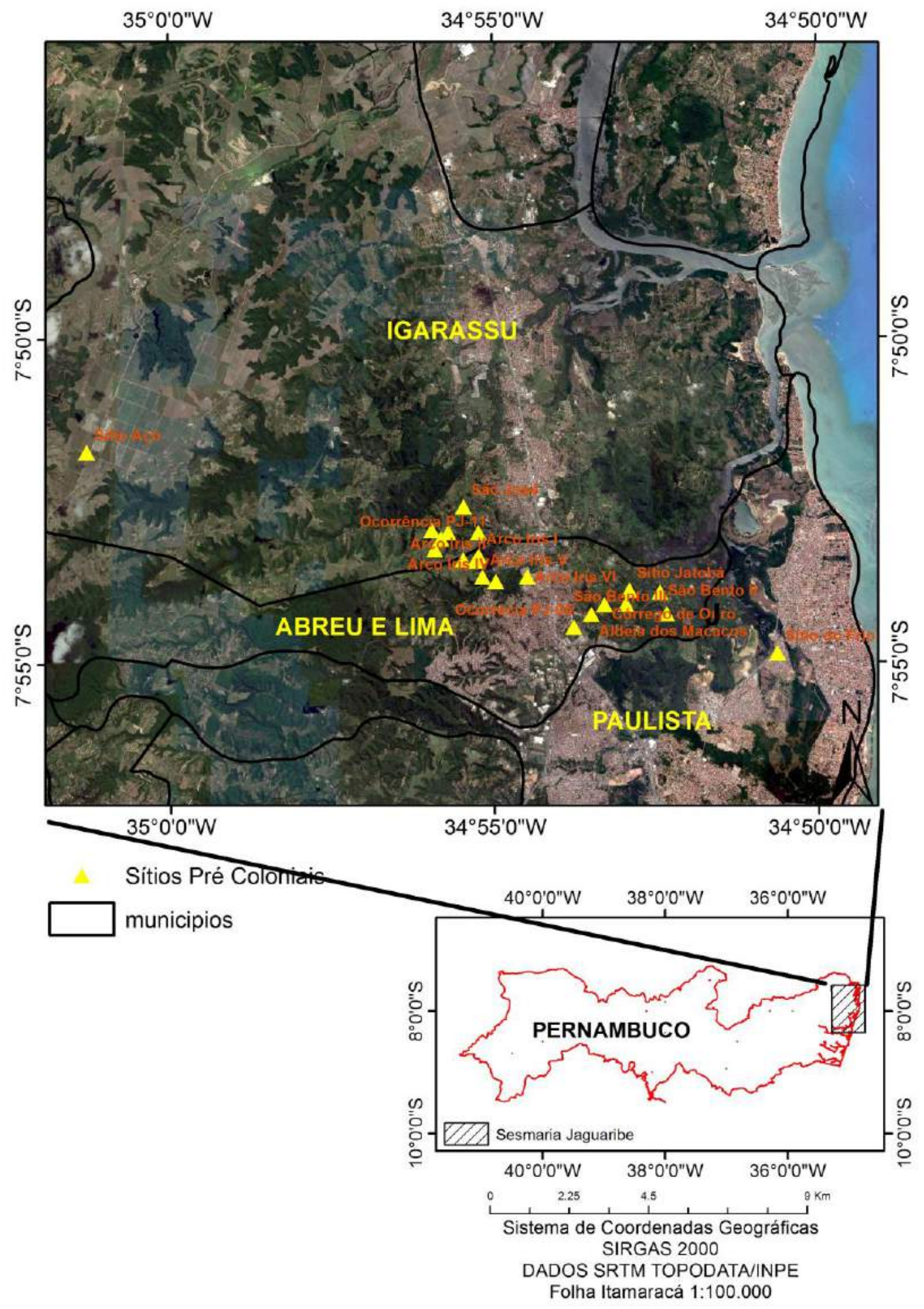

Figura 1. Localização da Sesmaria Jaguaribe. Fonte: Imagery Basemap ArcMap. Limites definidos de acordo com Oliveira, 2011. 


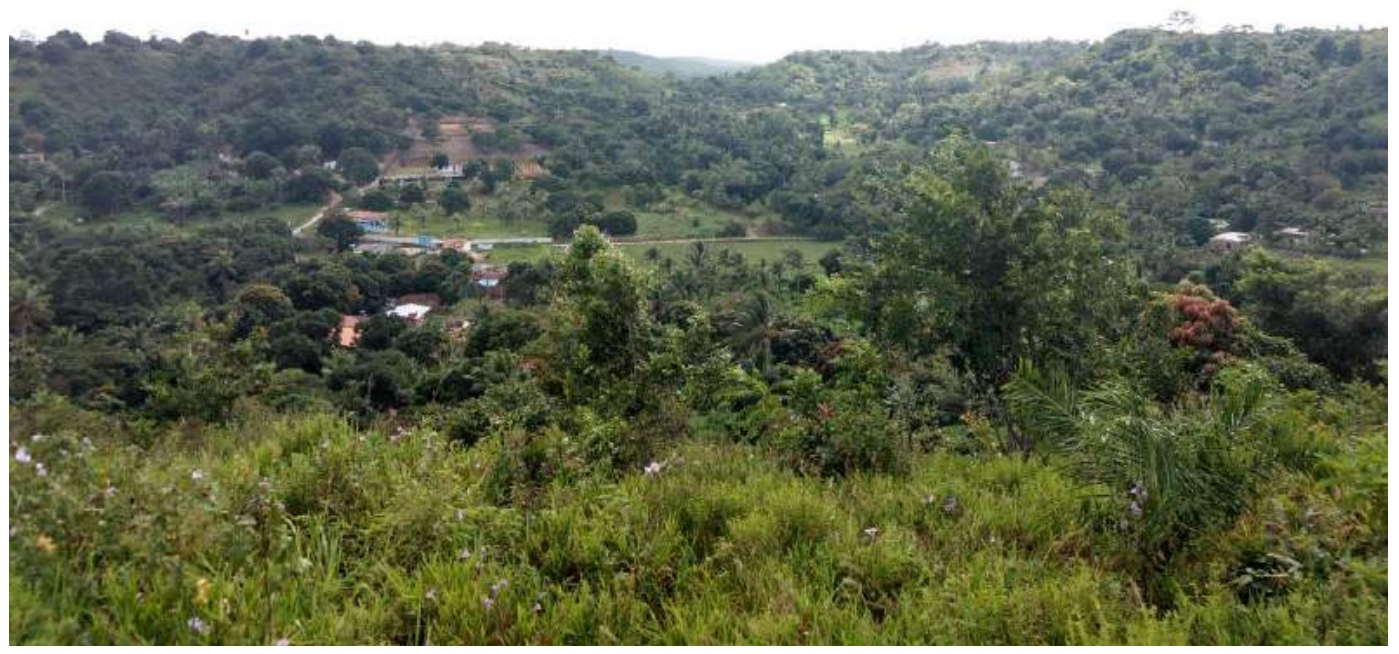

Figura 2: Tabuleiros da Sesmaria Jaguaribe. Fonte: Tavares, 2017.

Solos

Os grupos de solos encontrados na área são reflexos das altas taxas de intemperismo do arcabouço geológico. Essa taxa de produção de solos está vinculada ao clima Úmido desse setor costeiro, que permite a atuação dos mecanismos de intemperismo químico de forma mais intensa. Assim, a assembleia pedológica da área de estudo corresponde a solos ora profundos (com desenvolvimento de mantos argilosos) e bem drenados, ora com solos com grande concentração de matéria orgânica e com má drenagem, como os solos que ocorrem nas áreas rebaixadas, como as várzeas e ambientes de manguezal. Os solos predominantes na Sesmaria Jaguaribe são os latossolos, argissolos, solos de mangue (organossolos) e gleissolos.

\section{Sesmaria Jaguaribe}

Com o início da colonização das terras brasileiras por Portugal, foi implantado um sistema administrativo/econômico, para realizar uma melhor gerência para a nova colônia. Foi iniciado o sistema de capitanias hereditárias que foi adotado como um sistema de gerenciamento indireto, onde a Coroa Portuguesa abria mão de várias obrigações e gastos com a colonização, repassando a responsabilidade de particulares. O recebedor da capitania hereditária, o donatário, tinha entre outros direitos, realizar a doação de sesmarias para os colonizadores. "Sesmaria" foi um termo que indicava as terras abandonadas, onde não era observado o desenvolvimento de atividades econômicas ou a ocupação do espaço colonial. Pernambuco foi uma dessas capitanias, por conta da sua riqueza em aspectos naturais. A principal fonte 
econômica da capitania era a monocultura do açúcar, que foi explorada por mais de três séculos (Santos, 2009).

O plano de administração de Duarte Coelho baseava-se exatamente em implantar novos engenhos e distribuir sesmarias. Logo quando foi instalada a sede da capitania em Pernambuco, Duarte Coelho fez a doação dessas terras a Vasco Fernandes de Lucena (feitor e almoxarife da Fazenda Real), mediante a comunicação do donatário a D. João III (Santos, 2009; Oliveira, 2011).

Essa sesmaria estava situada ao norte de Olinda, no Jaguaribe. Esta foi a única sesmaria encontrada lavrada pelo donatário Duarte Coelho, e ficou registrada como Sesmaria Jaguaribe. Em 1550, Vasco Fernades enviou uma carta para o rei de Portugal, na qual ele fala que naquele ano já funcionavam cinco engenhos (Oliveira, 2011). Com a fundação desses engenhos, deu início a história da Sesmaria Jaguaribe que, em sua época, foi uma grande produtora de açúcar.

Dentre os produtos oriundos do sistema econômico da Sesmaria Jaguaribe pertinente a Fazenda de São Bento, não estava apenas a produção de açúcar, mas também na da cal que foi importante para o crescimento arquitetônico das cidades litorâneas da capitania de Pernambuco, no pescado, proveniente de seus estuários e também na exploração de suas matas.

\section{As Pesquisas Arqueológicas na Região}

As pesquisas arqueológicas na Sesmaria Jaguaribe, foram iniciadas em 2001, coordenadas pela Profa. Dra. Claudia Oliveira, e contou com a ajuda de alunos do Programa da Pós-Graduação em Arqueologia da Universidade Federal de Pernambuco, através do projeto "Prospecção de Sítios Arqueológicos da Sesmaria Jaguaribe, Litoral Norte do Estado de Pernambuco".

Segundo Oliveira (2011), a Sesmaria Jaguaribe tem sido alvo de estudos, pois vem registrando um conjunto de sítios que proporciona discussões, sobre os aspectos sociais da interação entre grupos de diferentes posições sociais, considerando o papel do europeu, do negro e do índio naquela área.

As pesquisas realizadas em 2001 serviram de base para outros trabalhos arqueológicos realizados na Sesmaria Jaguaribe, dentre eles estão o de Medeiros, 2005; Andrade, 2006; Silva, 2006; Santos, 2009; Oliveira et al, 2017; Cardoso et al, 2018 . Até então não se tinha 
informações sobre as populações indígenas no litoral, mas através dessas pesquisas realizadas na área, pôde ser visto uma grande quantidade de sítios pré-coloniais no litoral de Pernambuco. Apesar de tal esforço, muitos sítios pré-coloniais estão localizados em áreas loteadas, nas pequenas lavouras ou dentro de chácaras, o que inviabiliza novos trabalhos científicos.

$\mathrm{Na}$ área da Sesmaria Jaguaribe existe vinte e oito sítios arqueológicos. Os primeiros sítios foram localizados, através das pesquisas realizadas em 2001. A grande maioria dos sítios arqueológicos foi descoberta no projeto "Os primeiros engenhos coloniais da Sesmaria Jaguaribe - PE", no período de 2008 a 2010. Este projeto foi coordenado por Cláudia Oliveira professora do Curso de Arqueologia, na Universidade Federal de Pernambuco.

Dos vinte e oito (28) sítios arqueológicos, dezessete (17) deles são pré-coloniais (Tabela 1) e onze 11 são sítios históricos (Tabela 2), esses últimos já estão cadastrados no Instituto do Patrimônio Histórico e Artístico Nacional (Iphan - CNSA). Também foram registradas no período de 2008 a 2010, quatro ocorrências de vestígios pré-coloniais (Tabela 3).

Tabela 1: Sítios Pré-coloniais. Fonte: Oliveira, 2011.

\begin{tabular}{llll}
\hline $\mathbf{N o}$ & Sítios Pré-Coloniais & Longitude & Latitude \\
\hline 1 & Aldeia dos Macacos & 291458 & 9125806 \\
\hline 2 & Alto da Belenga & 292442 & 9126088 \\
\hline 3 & Arco Iris I & 288264 & 9127462 \\
\hline 4 & Arco Iris II & 288169 & 9127316 \\
\hline 5 & Arco Iris III & 287817 & 9127354 \\
\hline 6 & Arco Iris IV & 288749 & 9126738 \\
\hline 7 & Arco Iris V & 288366 & 9126868 \\
\hline 8 & Arco Iris VI & 289634 & 9126866 \\
\hline 9 & Campo do Oriente I & 287390 & 9128120 \\
\hline 10 & Campo do Oriente II & 288253 & 9128120 \\
\hline 11 & Córrego de Ouro & 291826 & 9126076 \\
\hline 12 & São Bento II & 293407 & 9126442 \\
\hline 13 & São Bento III & 293596 & 9125822 \\
\hline 14 & São José & 287828 & 9128858 \\
\hline 15 & Sítio Açú & 293596 & 9125822 \\
\hline 16 & Sítio do Campo & 293881 & 9119732 \\
\hline 17 & Sítio Jatobá & 292538 & 9126490 \\
\hline
\end{tabular}


Tabela 2: Sítios Arqueológicos históricos na área da Sesmaria Jaguaribe. Fonte: Oliveira, 2011.

\begin{tabular}{llll}
\hline CNSA & Nome & Município & UF \\
\hline PE00329 & Engenho Inhamã & Igarassu & PE \\
\hline PE00368 & Sítio Engenho do Meio - KM 361 & Igarassu & PE \\
\hline PE00374 & Maranguape & Paulista & PE \\
\hline PE00375 & Sítio do Frio & Paulista & PE \\
\hline PE00376 & Forno Salinas & Paulista & PE \\
\hline PE00337 & Engenho Jaguaribe & Abreu e Lima & PE \\
\hline PE00338 & São Bento & Abreu e Lima & PE \\
\hline PE00380 & Sítio Timbó & Abreu e Lima & PE \\
\hline PE00381 & Egenho Desterro & Abreu e Lima & PE \\
\hline PE00382 & Alto dos Macacos & Abreu e Lima & PE \\
\hline PE00383 & Alto Córrego de Ouro & Abreu e Lima & PE \\
\hline
\end{tabular}

Tabela 3: Ocorrências em contexto Pré-Colonial.

\begin{tabular}{llll}
\hline No & Ocorrências Pré-Coloniais & Longitude & Latitude \\
\hline 1 & Ocorrência PJ-05 & 290956 & 9125442 \\
\hline 2 & Ocorrência PJ-07 & 286928 & 9128192 \\
\hline 3 & Ocorrência PJ-10 & 287008 & 9127638 \\
\hline 4 & Ocorrência PJ-11 & 287193 & 9127944 \\
\hline
\end{tabular}

Os pesquisadores fizeram prospecções em algumas áreas que provavelmente seriam aldeias indígenas no período colonial, sendo possível verificar um número significativo de sítios précoloniais no litoral. Majoritariamente foram encontrados nos sítios prospectados muitos fragmentos de cerâmicas indígenas. Durante os trabalhos foram priorizados os setores elevados, que correspondem as colinas convexas e os topos planos dos tabuleiros (Figura 3), (Oliveira, 2011).

\section{Metodologia}

Inicialmente foi realizada uma pesquisa bibliográfica, para que se tivesse como referencial as abordagens teóricas já realizadas para padrões de assentamentos de grupos pré-coloniais. Também foi efetuado um trabalho quantitativo das pesquisas arqueológicas já realizadas na área de estudo, com o intuito de caracterizar os sítios arqueológicos pré-coloniais, inseridos na Sesmaria Jaguaribe. Para a compreensão das condições do meio físico-natural se fez necessário uma abordagem de caracterização do contexto geoambiental observando, mais atentamente, para a localização dos pontos de ocupação dos grupos pré-coloniais na paisagem. 
Foi adotado como base para esse trabalho, auxiliando na resolução de questões arqueológicas, os conceitos e métodos utilizados pelas geociências. Foram utilizados fundamentos da análise espacial, no intuito de observar as relações dos grupos pré-coloniais com o espaço físico na Sesmaria Jaguaribe. A análise espacial traz para a arqueologia, um estudo do comportamento humano mais relativista e contextualizado e serve para responder algumas perguntas, em relação aos critérios de ocupação dos grupos.

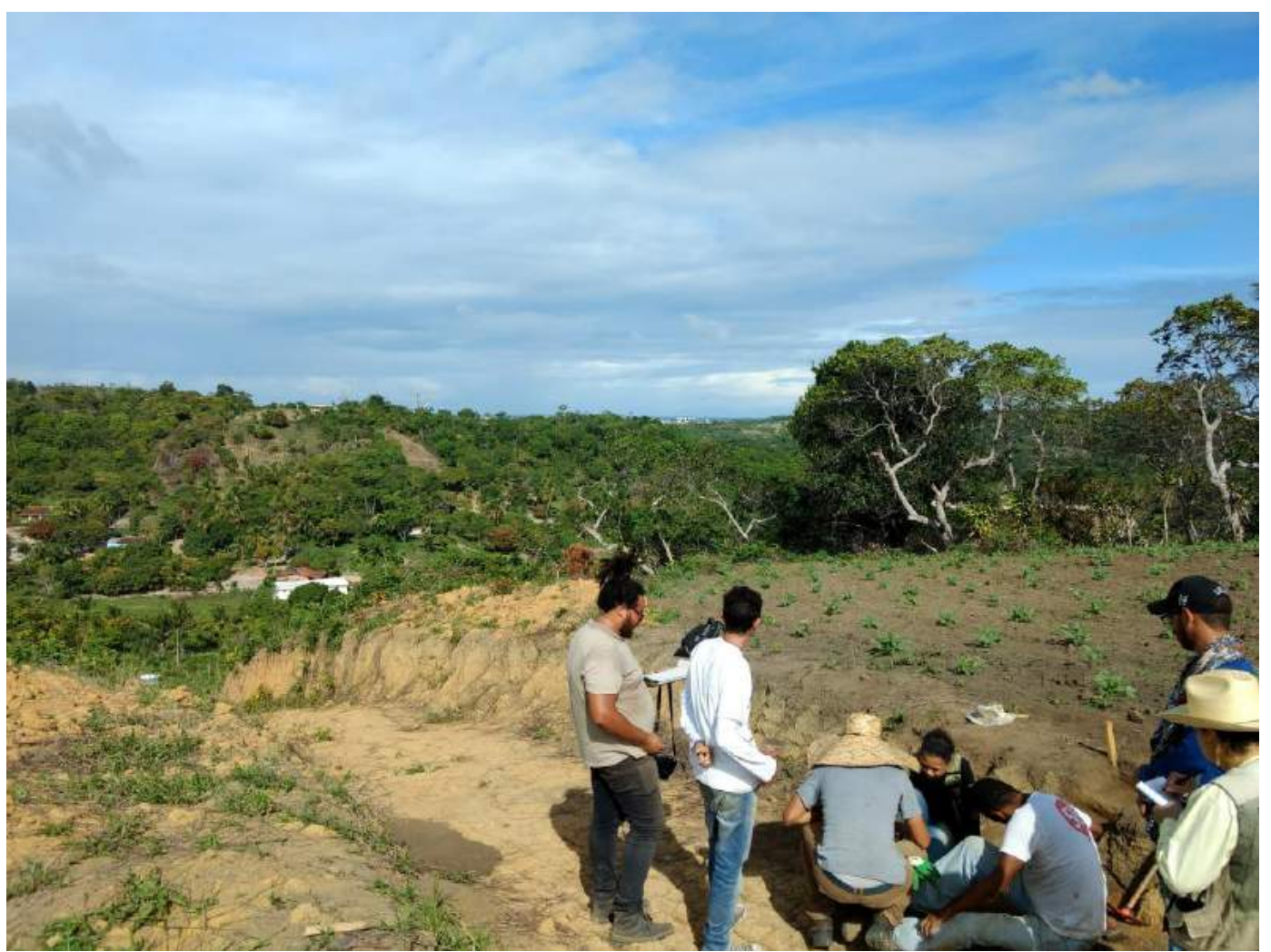

Figura 3: Sítio arqueológico Aldeia dos Macacos. O padrão dos sítios a céu aberto da sesmaria Jaguaribe, correspondem as áreas de topo das colinas e tabuleiros. Configurando um padrão de ocorrência dos sítios arqueológicos pré-coloniais nesse contexto geomorfológico. Foto: Bruno Tavares.

A base de dados utilizada no trabalho foram os relatórios de escavação (Oliveira, 2011) e algumas dissertações (Andrade, 2006; Silva, 2006; Santos, 2009) e alguns artigos como os trabalhos recentes de Oliveira et al (2017) e Cardoso et al (2018). A partir dessa base de dados, foi possível chegar ao universo de análise desta pesquisa. Como o objetivo do trabalho é identificar um padrão de sitos arqueológicos pré-coloniais, foi observado atentamente quantos sítios pré-coloniais existiam naquela área. Através dessa base de dados, foi totalizado 17 sítios pré-coloniais e 4 ocorrências. A base foi inserida em um SIG juntamente com mapas que 
representam as variáveis ambientais: Densidade do sítio, visibilidade, declividade, altimetria, geomorfologia, geologia, captação de recursos e aspecto da encosta.

Neste contexto, foram utilizados os dados do projeto Topodata/INPE, que tem como objetivo realizar o geoprocessamento de toda a cobertura do território brasileiro, bem como os dados do Serviço Geológico do Brasil - CPRM, além dos da Companhia Pernambucana de Recursos Hídricos - CPRH, atualmente denominados de Agência Estadual de Meio Ambiente.

Neste cenário foram pesquisados arquivos vetoriais e matriciais em fontes disponíveis de instituições que fazem esse processamento de dados espaciais e selecionados os melhores arquivos da área específica da Sesmaria Jaguaribe. Com tal documentação foi criado uma base de dados espaciais referente à área de pesquisa, utilizando o software ArcGIS 10.1 (licença acadêmica) para a gestão do SIG. Utilizando um arquivo raster pertinente à área da Sesmaria Jaguaribe, foi possível dar início a metodologia de análise, onde foram criados mapas de densidade do sítio, visibilidade, declividade, altimetria, geomorfologia, geologia, captação de recursos e aspecto da encosta.

\section{Resultados e Discussões}

As análises espaciais buscam organizar os referidos dados da área em uma base operacional, no caso, criando um SIG. Nesse sistema foram desenvolvidos os processos de relações entre as variáveis ambientais e os sítios pré-coloniais presentes na Sesmaria Jaguaribe. A análise geológica mostrou que os sítios pré-coloniais da Sesmaria Jaguaribe estão, em sua grande maioria, dispostos sobre a Formação Barreiras (Gráfico 1), que é a mais extensa dentre as unidades geológicas que ocorrem no segmento litorâneo. A disposição majoritária em setores com material da Formação Barreiras reflete o próprio posicionamento dessa unidade geológica que está vinculada aos setores de colinas e tabuleiros da Sesmaria Jaguaribe (Figura 4 e 5).

Em relação a compartimentação do relevo dos sítios arqueológicos pré-coloniais da Sesmaria Jaguaribe, os sítios estão dispostos majoritariamente no domínio dos tabuleiros (Figura 6). Tais tabuleiros consistem de superfícies sulcadas por uma rede de canais de densidade média a baixa (Gráfico 2). São 21 sítios em contexto de áreas elevadas. A concentração de sítios nos setores de topo dos tabuleiros (Figura 6) pode ter relação com o posicionamento de boa visibilidade e por se tratar de uma área com maior estabilidade em termos de processos erosivos. 


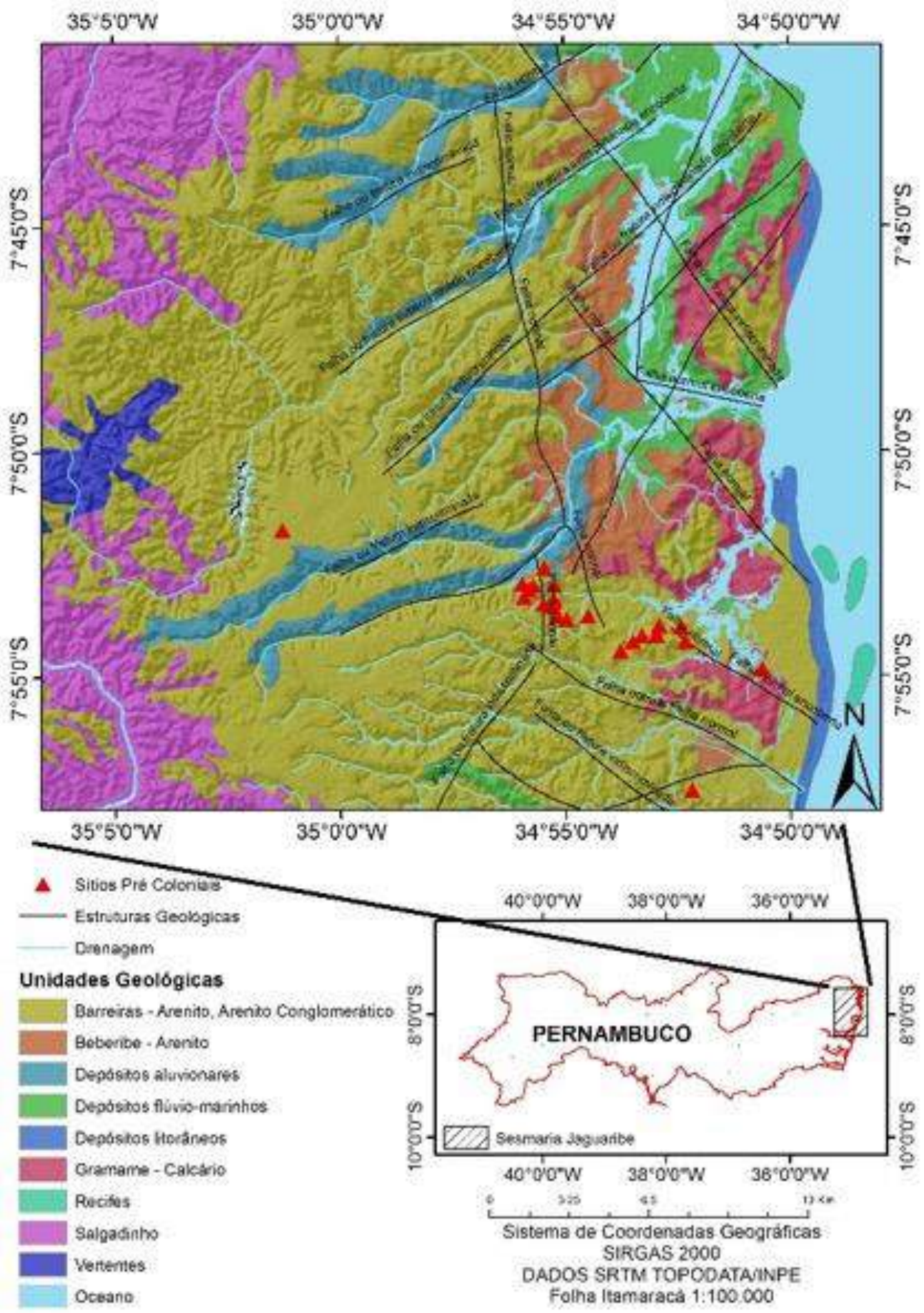

Figura 4. Domínios geológicos e compartimentos do relevo da Sesmaria Jaguaribe. Fonte: Elaborado pelos autores. 


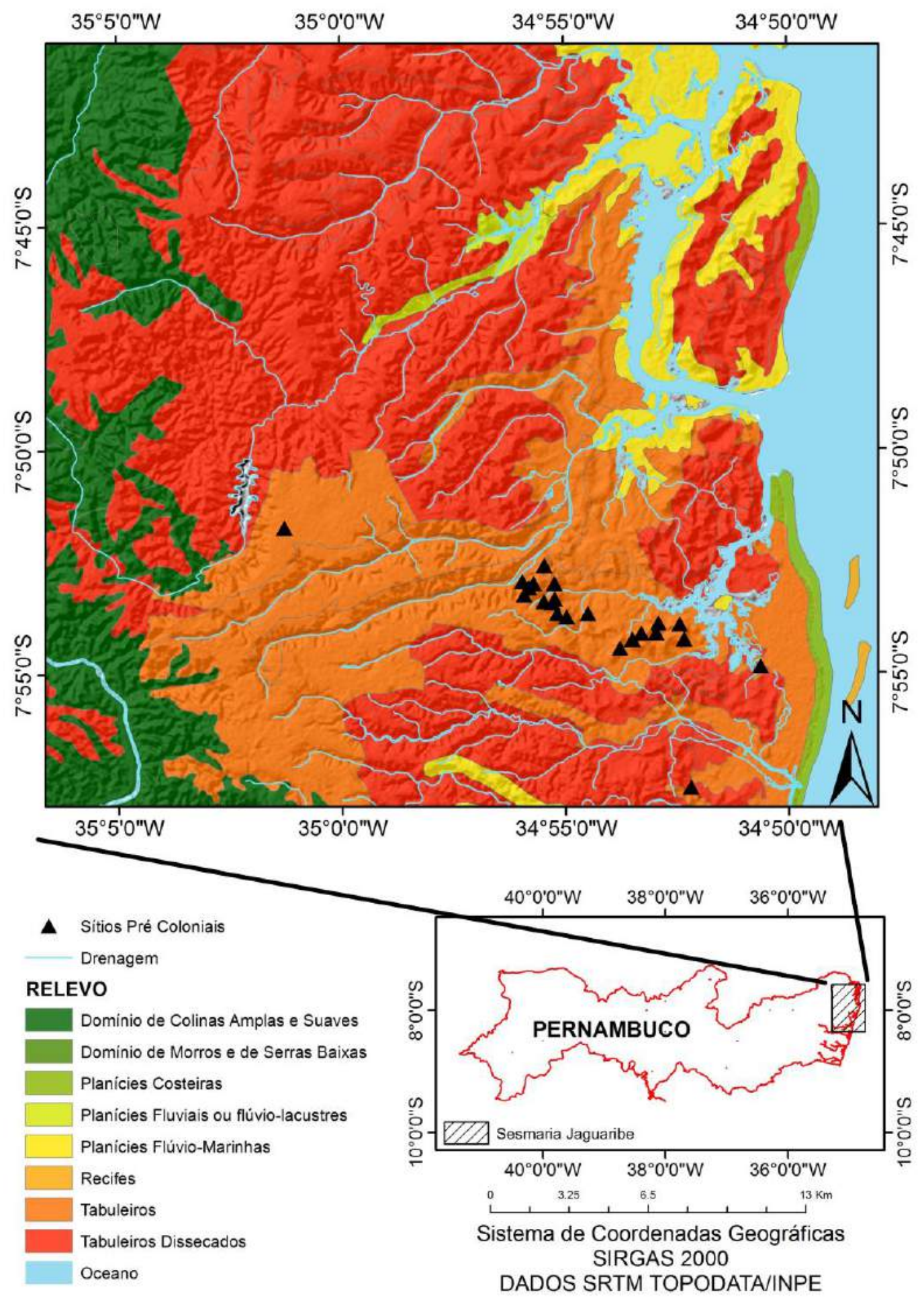

Figura 5. Compartimentação do relevo da Sesmaria Jaguaribe. Fonte: Elaborado pelos autores. 
Gráfico 1: Porcentagem de concentração de sítios por Unidade Geológica.

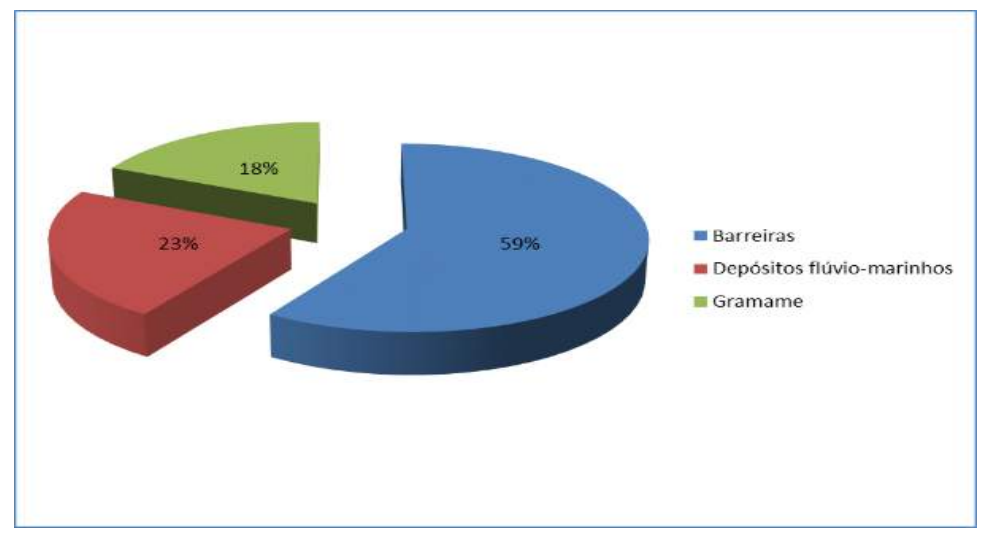

Gráfico 2: Concentração de Sítios por Compartimento de Relevo. Fonte: Elaborado pelos autores
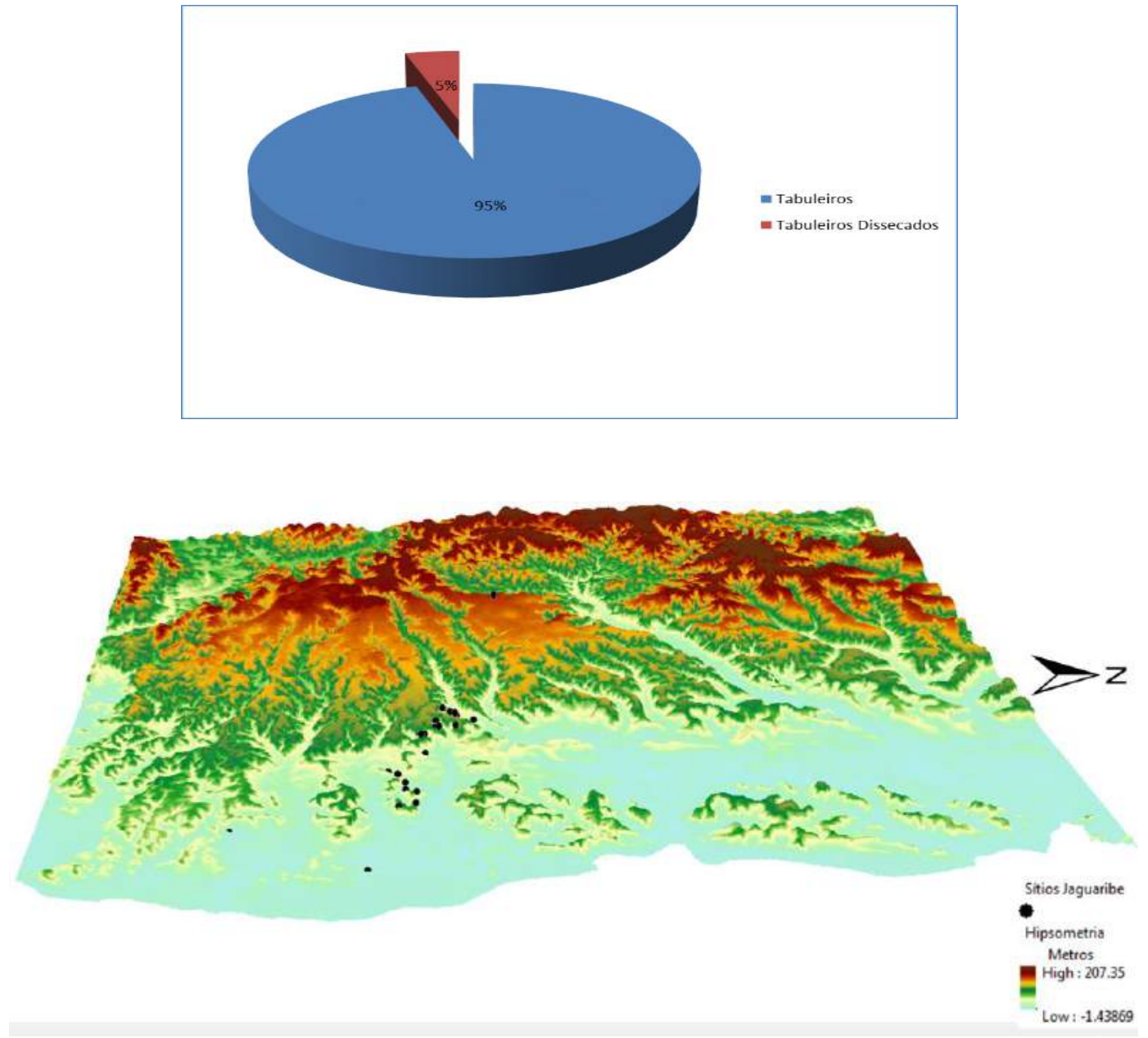

Figura 6: Bloco Diagrama indicando a elevação da área com as posições dos sítios. Destaque para a grande concentração de sítios nos setores de colinas e tabuleiros costeiros. Fonte: Dados topográficos Topodata/INPE, 2011. 
O mapa hipsométrico com as indicações dos perfis topográficos (Figura 7) pôde ajudar na visualização dos setores mais elevados. Foram confeccionados transectos do relevo (perfis) para demostrar a disposição geométrica das formas de relevo, que estão organizadas em sequências de colinas e vales com ampla dissecação. Os sítios pré-coloniais estão distribuídos majoritariamente nos topos das colinas (Gráfico 3, 4 e 5). A partir do mapa hipsométrico (Figura 7), também foi possível visualizar a questão da proximidade dos assentamentos com a rede hidrográfica da Sesmaria Jaguaribe, ela mostra que a maioria dos sítios arqueológicos précoloniais está próxima a recursos hidrológicos. Essa concentração de sítios próximos a esses recursos sugere que os grupos, procuravam se estabelecer em lugares próximos a fontes de água, facilitando assim, a captação de recursos.

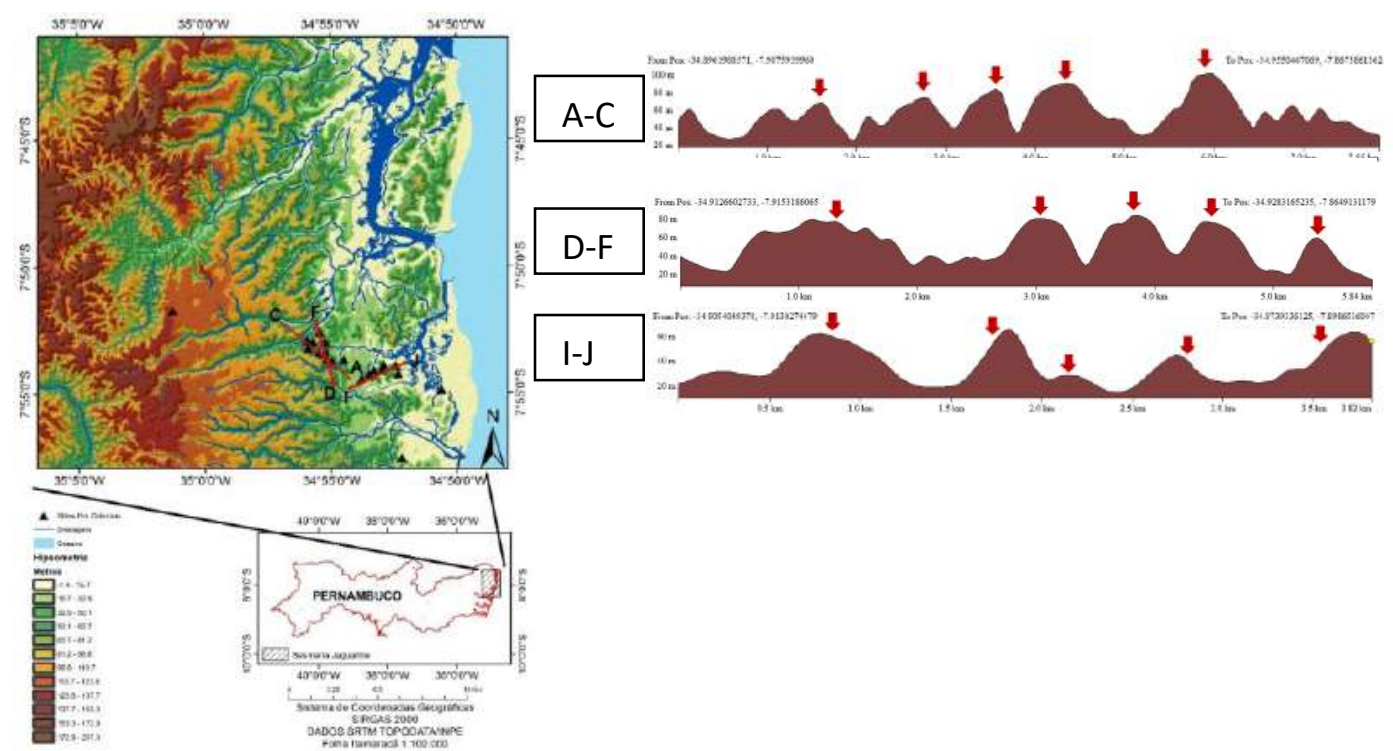

Figura 7: Mapa Hipsométrico com indicação dos perfis topográficos. Destaque para a posição dos sítios nas áreas de topo. Perfil topográfico A-C; Perfil topográfico D-F; Perfil topográfico I-J. Fonte: Elaborado pelos autores.

A declividade da área também foi um fator analisado neste trabalho. Para isso, a declividade do terreno foi classificada da seguinte forma: muito alta, alta, média, baixa e muito baixa. Os sítios arqueológicos pré-coloniais, em sua maioria estavam localizados em áreas com declividades muito baixas. De acordo com o mapa de declividade (Figura 8 e Gráfico 3), a maioria dos sítios está localizada em terrenos planos e suavemente ondulados e, apenas um ou dois sítios, situados em um terreno plano e suave ondulado. A declividade reflete diretamente a posição topográfica de topo dos tabuleiros, onde as maiorias dos sítios estão 
dispostas, também vale levar em discussão a posição dos sítios em porções da encosta superior, no limite entre a superfície plana (topo) e a porção convexa da encosta, o que conferia também alguns sítios estarem vinculados a áreas de declividade média a alta.

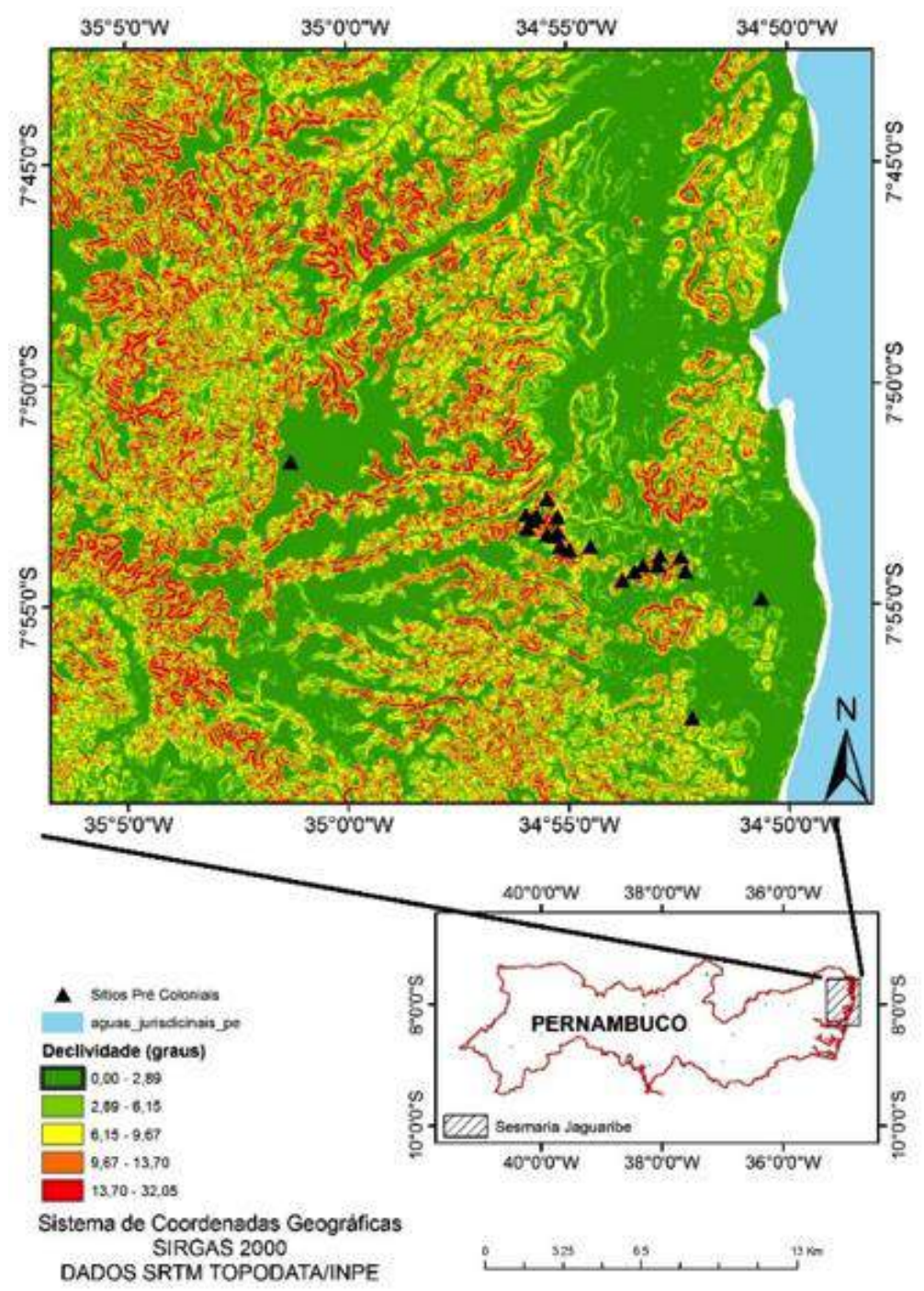

Figura 8: Mapa de declividade da Sesmaria Jaguaribe e gráfico relativo a porcentagem de sítios por classe de declividade. Fonte: Elaborado pelos autores.

Gráfico 3: Porcentagem de sítios por classe de declividade. Fonte: Elaborado pelos autores.

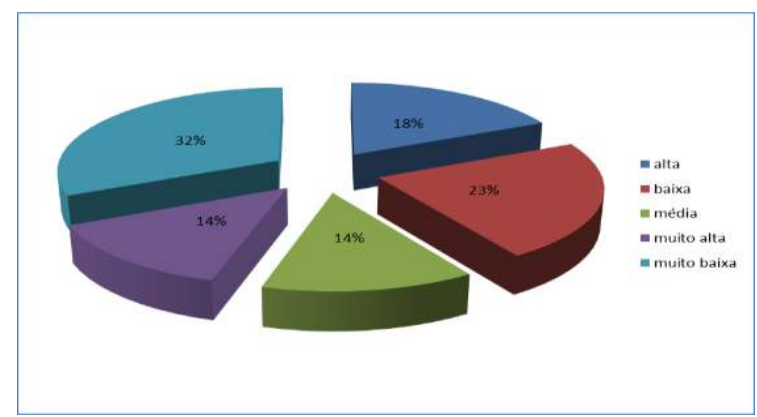


Em toda a área de estudo há duas diferentes áreas de concentração (Figura 9). Essas duas áreas de grande concentração de sítios pré-coloniais, podem mostrar um padrão de ocupação. Nesse caso, os grupos pré-coloniais estavam concentrados nos setores de topo de tabuleiros e próximos da encosta. Os sítios pré-coloniais estão em contexto de visibilidade entre eles e associados a setores mais elevados do relevo, onde o posicionamento do sítio permite uma observação de uma ampla área (Figura 10).

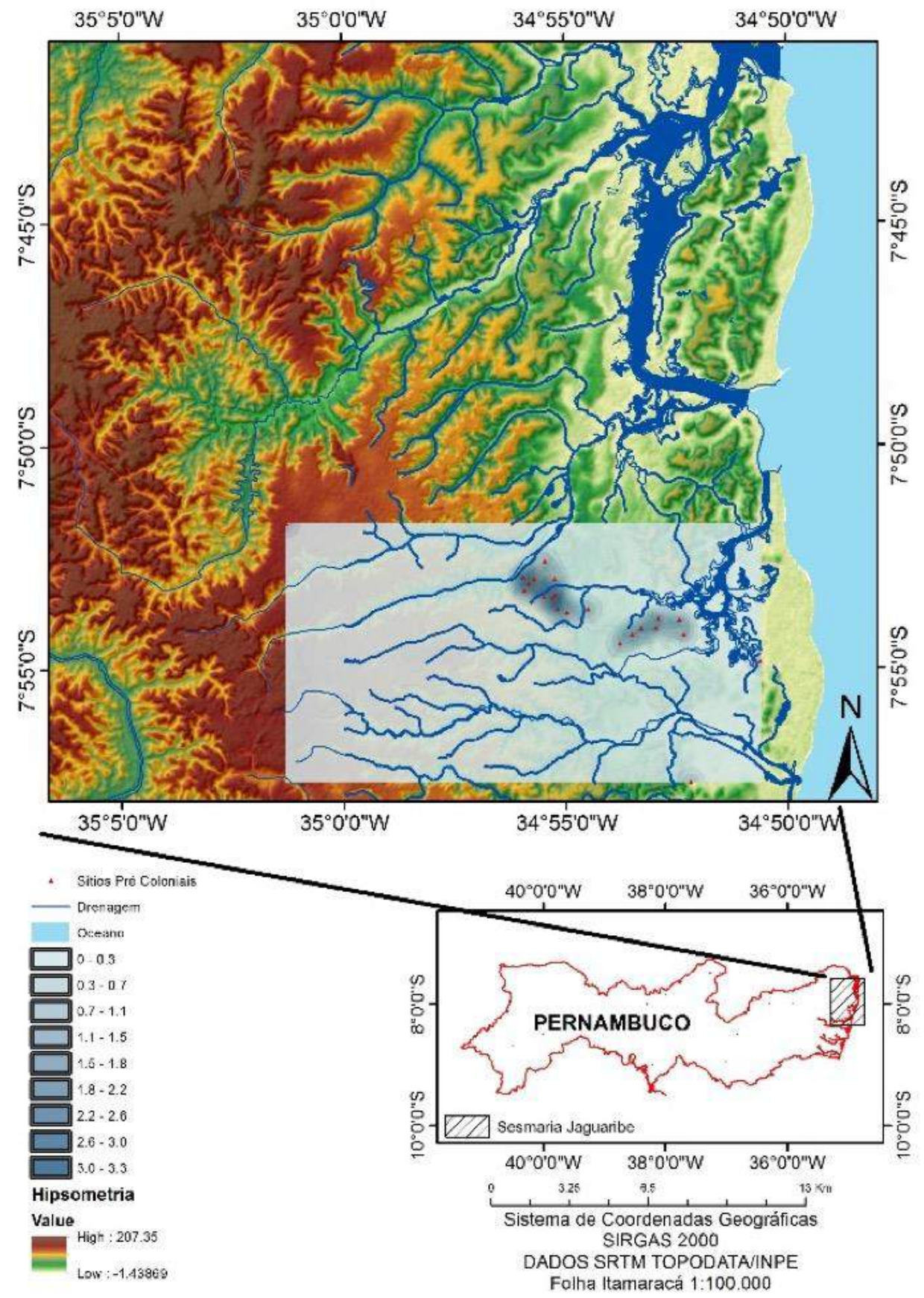

Figura 9: Densidade de sítios Pré-coloniais da Sesmaria Jaguaribe. Fonte: Elaborado pelos autores. 


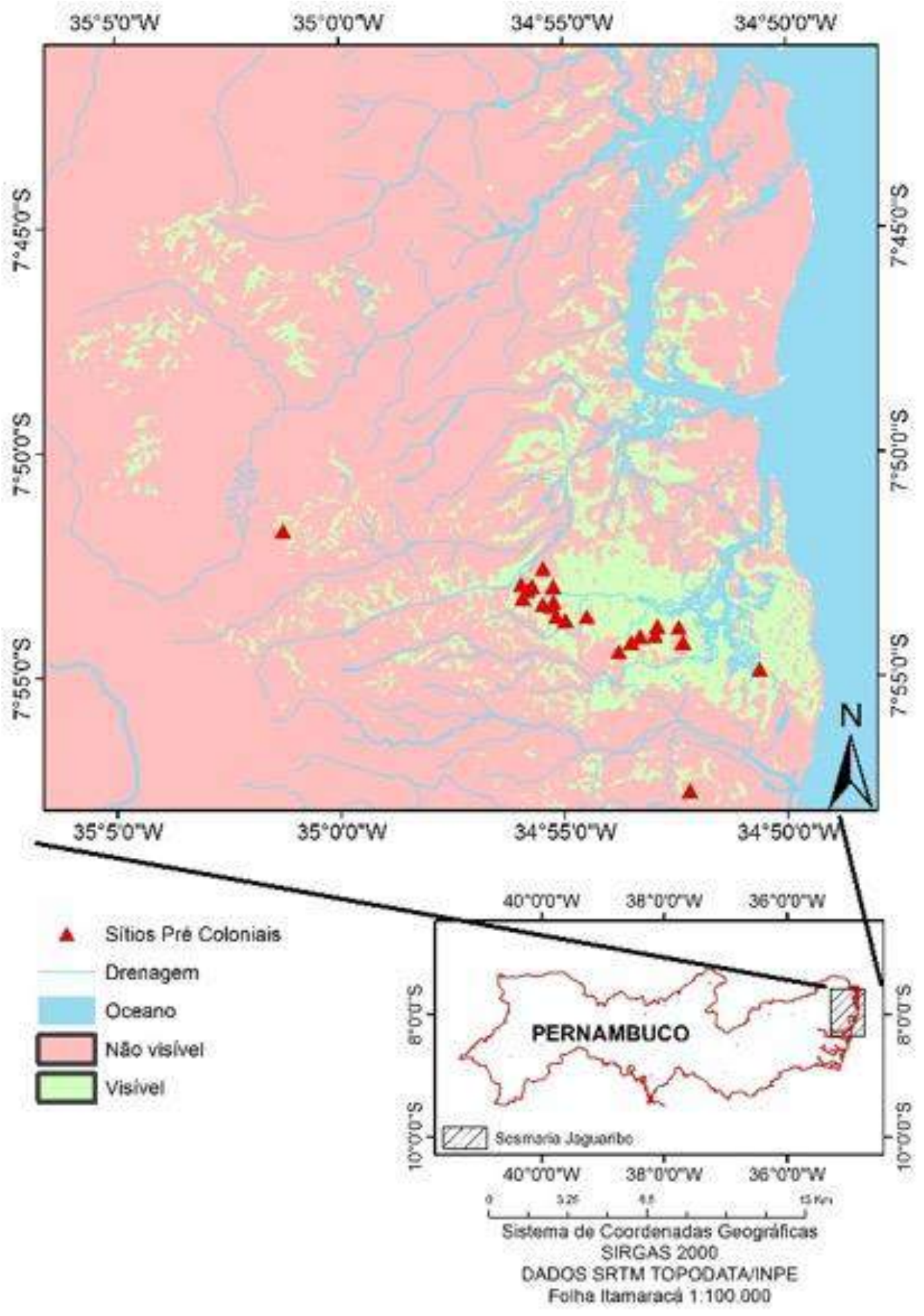

Figura 10: Visibilidade dos sítios pré-coloniais da Sesmaria Jaguaribe. Fonte: Elaborado pelos autores. 
Em relação à orientação dos sítios arqueológicos pré-coloniais da Sesmaria Jaguaribe (Figura 11, Gráfico 4) foi possível observar que uma grande parte dos sítios está localizado em encostas orientadas para Norte, Leste, Sudeste e Nordeste. A distribuição diversa de orientações de direção da encosta é um reflexo a alta taxa de dissecação do relevo, onde as encostas não possuem um controle estrutural na sua disposição na paisagem. No entanto é válido salientar que a preferência por posicionamentos voltados para leste, nordeste e sudeste pode ser uma condição dos próprios sistemas atmosféricos que vem do Atlântico, assim dessa forma, a escolha por essas direções possibilitava os grupos a visualizar a chegada dos sistemas climáticos advindos do oceano.

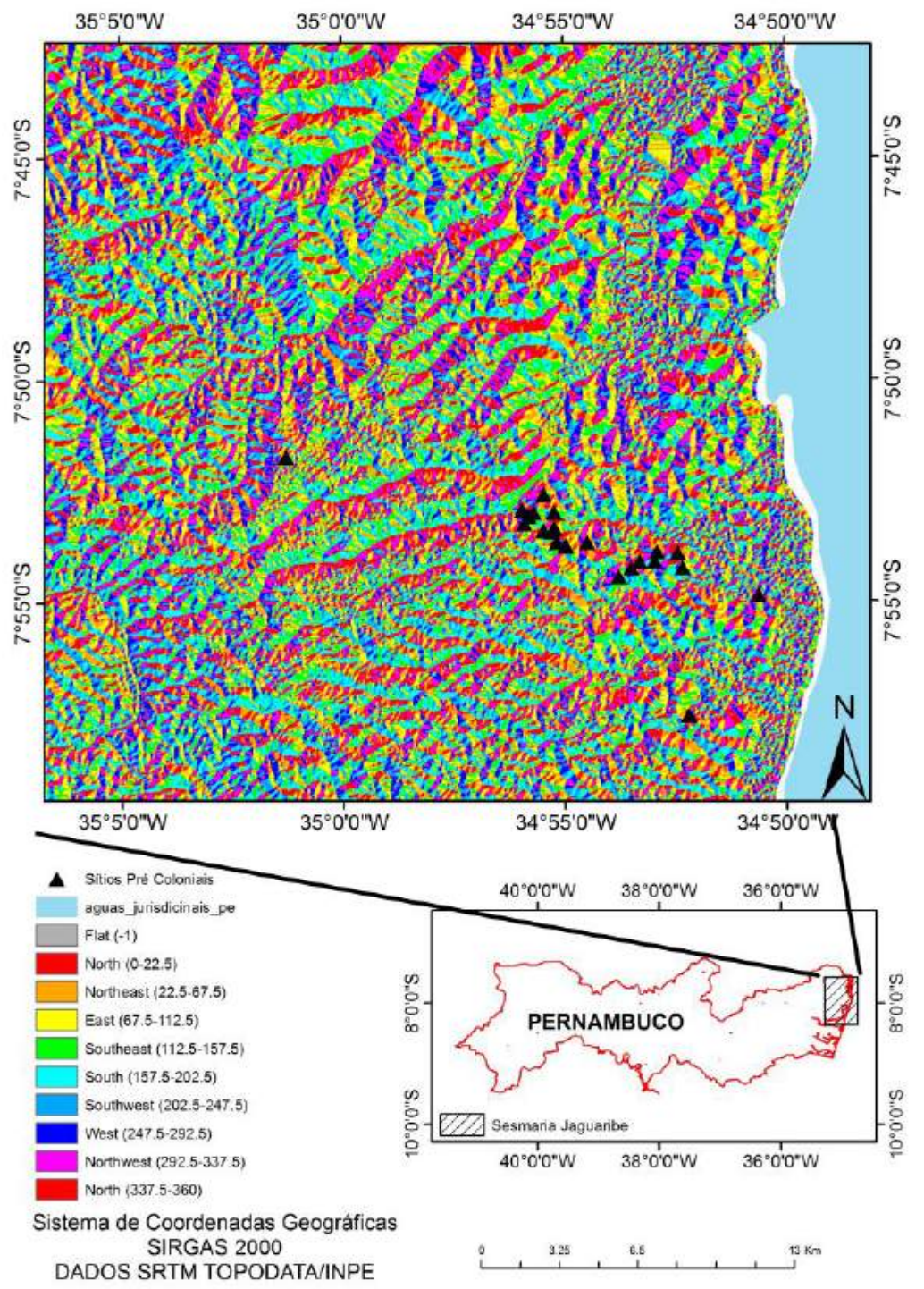

Figura 11: Orientação sítios pré-coloniais da Sesmaria Jaguaribe. Fonte: Elaborado pelos autores. 
Gráfico 4: Porcentagem da distribuição de sítios no contexto da direção das encostas. Fonte: Elaborado pelos autores.

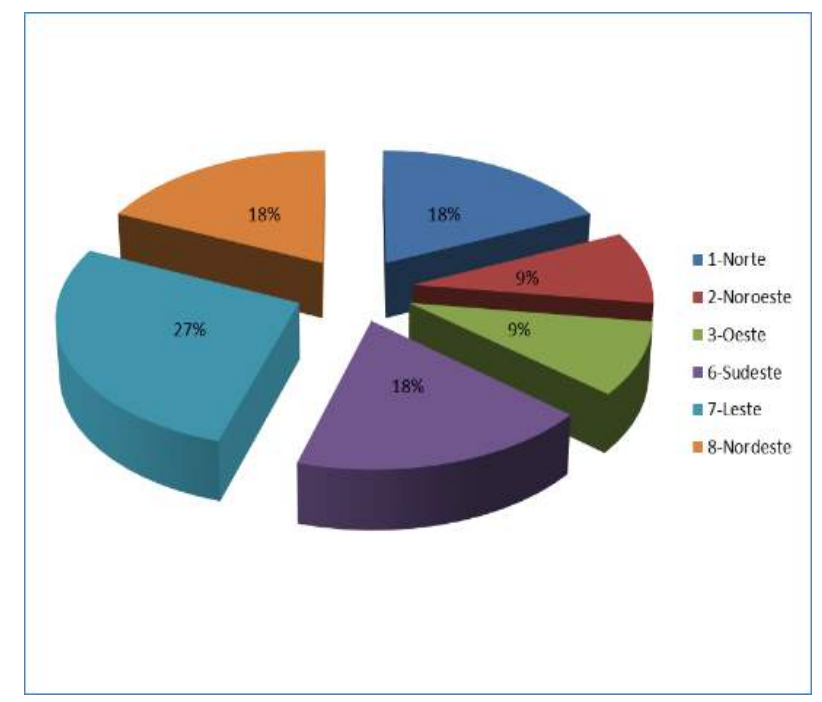

\section{Conclusões}

As análises realizadas sugerem que as variáveis ambientais e ecológicas atuaram como prováveis facilitadoras nas escolhas dos lugares de ocupação. A partir das interpretações foi possível perceber aspectos da conduta humana no passado. Os grupos humanos que habitaram a Sesmaria Jaguaribe tinham em suas escolhas algumas possibilidades que 0 ambiente natural disporia. Essas prováveis possibilidades, deve ter servido de impulso para suas decisões. No caso relação da relação ser humano x meio ambiente e como os grupos précoloniais da Sesmaria Jaguaribe habitaram e modificaram a paisagem, os elementos encontrados sugerem que eles procuravam áreas em topos de tabuleiros e próximos a encostas, por conta da captação de recursos, e também pra ter uma boa visibilidade da área do entorno. A geomorfologia pode ter atuado como um fator determinante, uma vez que os setores escolhidos correpondem as áreas com maior estabilidade dos processos erosivos, uma vez que o setor da Mata Atlântica Pernambucana é caracterizado por processos erosivos intensos impulsionados pela dinâmica climática úmida. O clima e o avanço dos sistemas atmosféricos provindos do Atlântico também podem ter contribuído para o posicionamento das ocupações em relação ao direcionamento das encostas, basicamente todas voltadas para o Oceano. Para o caso dos sítios da Sesmaria Jaguaribe, sugere-se que os elementos integrados da paisagem, Geologia X Geomorfologia X Clima podem ter sido os fatores que possibilitaram a ocupação desses povos nesse contexto da paisagem costeira pernambucana. 


\section{Referências}

ANDRADE, A. P. G. (2006). A casa de vivenda do Sítio São Bento de Jaguaribe: uma reconstituição arqueológica. Dissertação (Mestrado em Arqueologia). Universidade Federal de Pernambuco, 162p.

BEBER, M. V. (2004). O sistema de assentamento dos grupos ceramistas do planalto Sul-Brasileiro: O caso da tradição Taquara/Itararé. São Leopoldo. Tese (Doutorado em Arqueologia). Universidade do Vale do Rio dos Sinos.

BINFORD, L. R. (1962). Archaeology as Anthropology. American Antiquity, Salt Lake City, n. 2, p. 217-225, v. 28.

BOADO, F. C. (1991). Construcción social del espacio y reconstrucción arqueológica del paisaje. Boletín de Antropologia Americana, 5-29.

BOADO, F. C. (1999). Del terreno al espacio: planteamientos y perspectivas para la arqueología del paisaje. Capa-critérios y convenciones em arqueología del paisaje.

BUTZER, K. (1989). Arqueología una ecología del hombre. Barcelona: Ediciones Bellaterra.

CARDOSO, R. A. ; AMARAL, A. M. ; OLIVEIRA, C. . Engenhos Que Caem e Casas Que Se Erguem: Estudo de Caso do Engenho Jaguaribe, Abreu e Lima, PE. In: Cláudia Oliveira; Neuvânia Curty Guetti; Scott Allen. (Org.). Arqueologia de engenhos: arqueologia e conservação do patrimônio cultural de Pernambuco. 1ed.Recife: Editora UFPE, 2018, v. 3, p. 101-121.

CLARKE, D. L. (1977). Spatial Archaeology. Boston: Academic Press.

CPRH. (2001). Diagnóstico Socioambiental do Litoral Norte de Pernambuco. Recife.

DEAN, W. (1996). A ferro e fogo: a história e a devastação da Mata Atlântica brasileira. 1. ed. São Paulo: Cia. das Letras.

CONOLLY, J. \& LAKE, M. (2009). Sistema de información geográfica aplicada a la arqueología. Barcelona: Edición Bellaterra.

MORAIS, J. L. (2000). Tópicos de Arqueologia da Paisagem. Revista do Museu de Arqueologia e Etnologia, 3-30.

MUTZENBERG, D. S. (2007). Gênese e ocupação pré-histórica do sítio arqueológico Pedra do Alexandre: Uma abordagem a partir da caracterização paleoambiental do vale do Rio Carnaúba - RN. Tese (Doutorado em Arqueologia), UFPE.

MADEIRA, L. R. (2016). Padrões de abrigos com pinturas rupestres no parque nacional do Catimbau, PE. Trabalho de Conclusão de Curso em Arqueologia da UFPE.

MEDEIROS, M. C. (2005) Reconstituição de uma fazenda colonial: estudo de caso - Fazenda de São Bento de Jaguaribe. Dissertação (Mestrado em Arqueologia), UFPE. 
OLIVEIRA, C. A. (2011). Relatório final: Os primeiros engenhos coloniais da Sesmaria Jaguaribe - PE. UFPE - Departamento de Arqueologia, 174 p.

OLIVEIRA, C.; JIMENEZ, P. ; SILVA JUNIOR, L. S. . O Engenho Jaguaribe: primeiros resultados da pesquisa arqueológica. In: Cláudia Oliveira; Neuvânia Curty Guetti; Scott Allen. (Org.). Arqueologia de engenhos: tecnologias, produção e consumo. 1ed.Recife: Editora UFPE, 2017, v. 2, p. 07-39.

SANJUÁN, L. G. (2005). Introducción al Reconocimiento y Análisis Arqueológico del Territorio. Barcelona: Ed. Ariel.

SANTOS, P. J. (2006). Aplicação de Sistemas de Informação Geográfica em Arqueologia. Lisboa: Dissertação (Mestrado em Ciência e Sistemas de Informação Geográfica). Instituto Superior de Estatística e Gestão de Informação da Universidade Nova de Lisboa.

SANTOS, M. H. (2009). Uma política de preservação em defesa do patrimônio cultural: a antiga Sesmaria Jaguaribe - Abreu e Lima/PE. Dissertação (Mestrado em Arqueologia). Universidade Federal de Pernambuco, 118p.

SILVA, F. A. J. (2006). O cativeiro rural colonial: reconstituição arqueológica da senzala da fazenda de São Bento de Jaguaribe Município de Abreu e Lima, Pernambuco. Dissertação (Mestrado em Arqueologia). Universidade Federal de Pernambuco, 129p.

WILLEY, G.R. (1953). Prehistoric Settlement Patterns in the Virú Valley, Peru. Bureau of American Ethnology Bulletin, 155. 